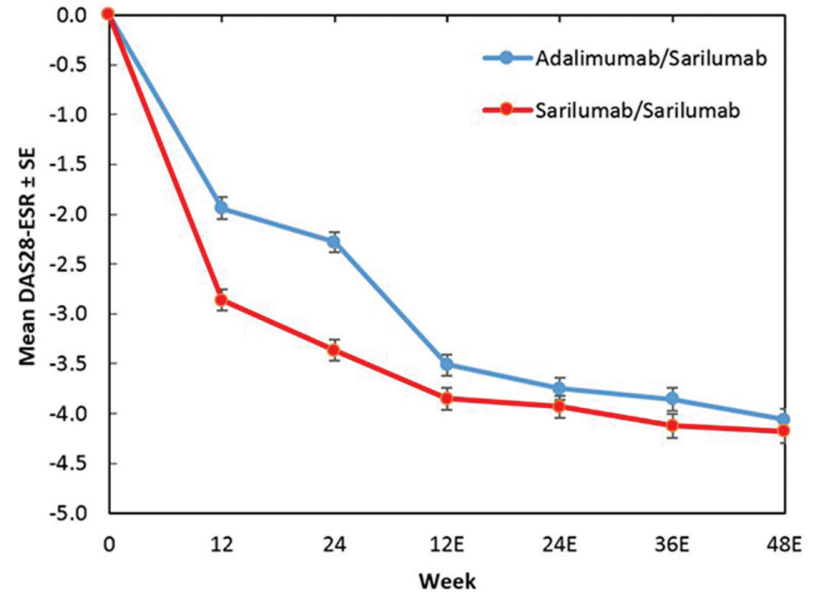

Figure 1 Mean V from baseline in DAS28-ESR (OLE population; as observed).Conclusions: Switching from adalimumab ( $40 \mathrm{mg}$ q2w) to sarilumab monotherapy (200 $\mathrm{mg}$ q2w) improved the signs and symptoms of RA to a similar level as continuous sarilumab treatment, and was associated with a lower HAQ-DI score, which may have resulted in numerical differences in ACR responses between the two groups.

Acknowledgements: Study funding and medical writing support (Vicki Cronin, Adelphi) provided by Sanofi and Regeneron Pharmaceuticals, Inc.

Disclosure of Interest: G. R. Burmester Grant/research support from: AbbVie, Pfizer, UCB, Roche, Consultant for: AbbVie, Lilly, Merck Sharpe \& Dohme, Pfizer, Sanofi, Roche, UCB, Speakers bureau: AbbVie, Lilly, Merck Sharpe \& Dohme, Pfizer, Sanofi, Roche, UCB, G. St John Shareholder of: Regeneron, Employee of: Regeneron, M. Iglesias-Rodriguez Employee of: Sanofi, C.-C. Hu Shareholder of: Sanofi, Consultant for: Astellas, Employee of: Sanofi, Quintiles, T. Raskina: None declared, H. Amital Grant/research support from: Pfizer, Abbvie, Yansen, Consultant for: Pfizer, Merck Sharpe \& Dohme, Speakers bureau: Pfizer, Merck Sharpe \& Dohme, Yansen, Sanofi, Bristol-Myers Squibb, A. Gomez Centeno Grant/ research support from: Boehringer Ingelheim, Celltrion, Galapagos-Gilead, Lilly, Novartis, Pfizer, Roche, Sanofi, UCB, YL Biologics, Consultant for: Abbvie, Biogen, Bristol-Myers Squibb, Celgene, Gebro, Hospira, Lilly, Merck Sharpe \& Dohme, Pfizer, Roche, Rubio, Sandoz, Sanofi, Speakers bureau: Abbvie, BristolMyers Squibb, Gebro, Janssen, Lilly, Menarini, Merck Sharpe \& Dohme, Pfizer, Roche, Rubio, UCB, Sanofi, A. Rubbert-Roth Consultant for: Abbvie, BristolMyers Squibb, Chugai, Roche, Merck Sharpe \& Dohme, Pfizer, Lilly, Hexal/Novartis, Janssen, Sanofi, Speakers bureau: Roche, Chugai, Sanofi, Lilly DOI: 10.1136/annrheumdis-2018-eular.1372

\section{SAT0184 THE EFFECT OF SMOKING ON RESPONSE TO TUMOR NECROSIS FACTOR-ALPHA INHIBITOR TREATMENT IN ANKYLOSING SPONDYLITIS PATIENTS: RESULTS FROM THE TURKBIO REGISTRY}

H. Yarkan Tuğsal ${ }^{1}$, G. Can², S. Çapar ${ }^{3}$, B. Zengin ${ }^{1}$, G. Kenar ${ }^{1}$, S. Akar ${ }^{4}$

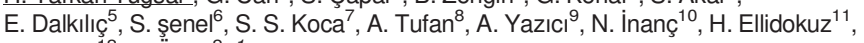
N. Akkoç ${ }^{12}$, F. Önen'. ${ }^{2}$ Rheumatology, Dokuz Eylül University Faculty Of Medicine, IzmiR, ${ }^{2}$ Rheumatology, Dokuz Eylül University Faculty Of Medicine, ${ }^{3}$ Department Of Statistics, Dokuz Eylül University Health Sciences Institute, Izmir,

${ }^{4}$ Rheumatology, Katip Çelebi University Hospital, İzmir, ${ }^{5}$ Rheumatology, uludaĞ University faculty of medicine, bursa, ${ }^{6}$ Erciyes University Faculty Of Medicine, Kayseri, ${ }^{7}$ Firat university faculty of medicine, ElaziĞ, ${ }^{8}$ Rheumatology, Gazi University Faculty Of Medicine, Ankara, ${ }^{9}$ Rheumatology, Kocaeli University Faculty Of Medicine, Izmit, ${ }^{10}$ Rheumatology, Marmara UniVersiTy Faculty Of MediciNe, Istanbul, ${ }^{11}$ Department Of Statistics, Dokuz Eylül University Faculty Of Medicine, Izmir, ${ }^{12}$ Rheumatology, Private Practice, Izmir, Turkey

Background: Although there is good evidence that smoking has a dosedependent impact on structural damage progression in ankylosing spondylitis (AS) the evidence is poor for its impact on disease activity, physical mobility, life quality and treatment response.

Objectives: We aimed to investigate the impact of smoking on disease acitivity, treatment adherence and treatment response in Turkish patients with AS treated with their first tumour necrosis factor-alpha inhibitor (TNFi) therapy in a real-life cohort.

Methods: 561 patients fulfilling the modified New York criteria for AS and treated with their first TNFi therapy since 2011 from 8 centers in Turkey were included in the analysis. Treatment response was evaluated as achievement of "BASDAI50" or "ASDAS Clinically important improvement (CII)" at the 3-months' and 6 months' visits. Clinical and demographic parameters were compared between current/ never and current/previous smoker groups. Demographic and descriptive data are presented by medians/interquartile ranges (IQRs). Groups were compared by non- parametric tests $\left(\mathrm{x}^{2}\right.$, Kruskal Wallis and Mann Whitney tests). Kaplan Meier plots, Cox and logistic regression analyses were calculated for treatment adherence and treatment response.

Results: Among 561 AS patients included in the study, 506 (90\%) had known smoking status (37\% current, $35 \%$ never, $17 \%$ previous smokers). The median follow-up time was 1.9 years (IQR $0.85-3.5$ ) and disease duration was 3.1 years $(0,6-7,7)$. At baseline, current smokers were younger (34, IQR 29-41) compared with never (38, IQR 30-46 p=0.007) and previous smokers (42, IQR 34-49 $p<0,001)$. Current smokers had male predominance $(n=148,43.9 \% ; n=85$, $25.2 \%)$; lower erythrocyte sedimentation rate $(28 \mathrm{~mm} / \mathrm{h}(13-42) ; 34 \mathrm{~mm} / \mathrm{h},(20-$ 49) and higher change in BASMI (40, IQR 10-57.5; 10, IQR 4-30) compared with never smokers (all $p<0.005$ ). HLA status, body mass index, CRP, baseline disease indexes (BASDAI, BASFI, BASMI, HAQ, ASDAS) and treatment response was not found to be different between current and never smoker patients in our population (table 1). In multivariate analysis, male (OR:1,98; $95 \% \mathrm{Cl}(1,39-2,82)$, $\mathrm{p}<0,01)$, HLA positive $(\mathrm{OR}: 1,54 ; 95 \% \mathrm{Cl}(1,08-2,18), p=0,016)$ and active DMARD user (OR:1,84; $(95 \% \mathrm{Cl} 1,12-3,01) \quad \mathrm{p}=0,015)$ patients had better treatment response and treatment adherence ((HR:1,93; $95 \% \mathrm{Cl}(1,36-2,73)$; HR:1,60; $95 \% \mathrm{Cl}(1,13-2,27) ; \mathrm{HR}: 1,80 ; 95 \% \mathrm{Cl}(1,10-2,95)$ all $\mathrm{p}<0,005)$ but smoking status were not significant $(p>0,05)$.

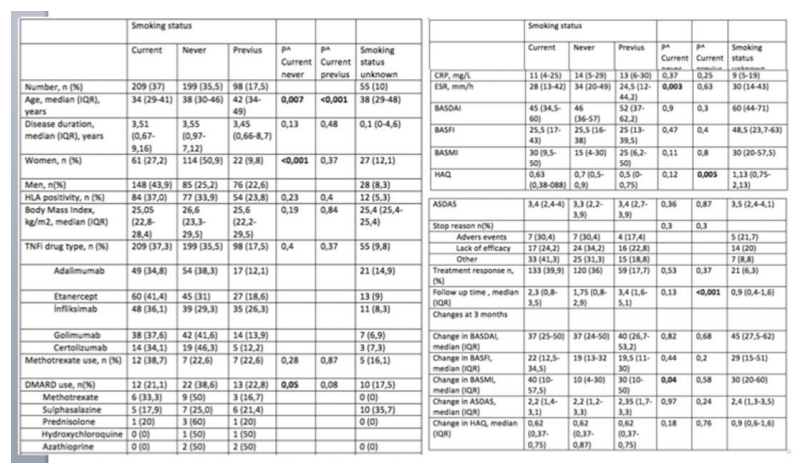

Conclusions: In this study of TNFi-treated AS patients in clinical practice, smoking was not found to be associated with disease activity, treatment response and treatment adherence.

Disclosure of Interest: None declared

DOI: 10.1136/annrheumdis-2018-eular.6586

\section{SAT0185 CERTOLIZUMAB PEGOL SERUM LEVELS $\geq 20$ MG/L ARE ASSOCIATED WITH IMPROVEMENT IN DAS28 IN RHEUMATOID ARTHRITIS PATIENTS. DATA FROM THE NOR-DMARD STUDY}

J. E. Gehin ${ }^{1}$, S. W. Syversen ${ }^{2}$, D. J. Warren ${ }^{1}$, G. L. Goll ${ }^{2}$, J. Sexton ${ }^{2}$, E. K. Strand ${ }^{3}$, T. K. Kvien ${ }^{2}$, N. Bolstad ${ }^{1}$, E. Lie ${ }^{2}$. ${ }^{1}$ Department of Medical Biochemistry, Oslo University Hospital, ${ }^{2}$ Department of Rheumatology, Diakonhjemmet Hospital, Oslo, ${ }^{3}$ Lillehammer Hospital for Rheumatic Diseases, Lillehammer, Norway

Background: Measurement of serum drug levels can help clinicians tailor treatment with TNF-inhibitors. An association between certolizumab pegol (CP) serum levels and treatment response in rheumatoid arthritis (RA) patients (pts) has previously been demonstrated in a prospective observational study (1). These results need to be confirmed in other studies, with particular focus on finding an optimal therapeutic serum level for $\mathrm{CP}$.

Objectives: To examine the association between serum CP drug levels and treatment response in RA pts and to identify a therapeutic target level.

Methods: Patients with a clinical diagnosis of RA starting standard treatment with $\mathrm{CP}$ included in the NOR-DMARD registry with biobank sample at 3 months follow-up, were included in the present analyses. Serum drug levels (non-trough) were analysed with an in-house immunofluorometric assay automated on the AutoDELFIA immunoassay platform. We studied association between serum CP level and $\triangle D A S 28$ and EULAR good/moderate response at 3 months by multivariable linear and logistic regression analyses, respectively, adjusting for age, sex and prior bDMARD $(\mathrm{Y} / \mathrm{N})$.

Results: In 91 included patients, median serum drug level at 3 months follow up was $34.7 \mathrm{mg} / \mathrm{L}$ (17.6-44.6). Response data were available in 81/91 patients. Serum CP level $\geq 20 \mathrm{mg} / \mathrm{L}$ was associated with greater improvement in DAS28 at 
3 months $(\beta=0.89$ (95\% Cl $0.03-1.74), P=0.04 .44 .4 \%$ of pts with CP level $<20$ $\mathrm{mg} / \mathrm{L}$ achieved EULAR response after 3 months treatment, while $73.5 \%$ of pts with CP level $20-40 \mathrm{mg} / \mathrm{L}$ and $55.2 \%$ with $\geq 40 \mathrm{mg} / \mathrm{L}$ were responders. However, the difference in EULAR response between pts with CP level $\geq 20 \mathrm{vs.}<20 \mathrm{mg} / \mathrm{L}$ did not reach statistical significance (OR $1.5(95 \% \mathrm{Cl} 0.5-5.1), \mathrm{P}=0.48)$.
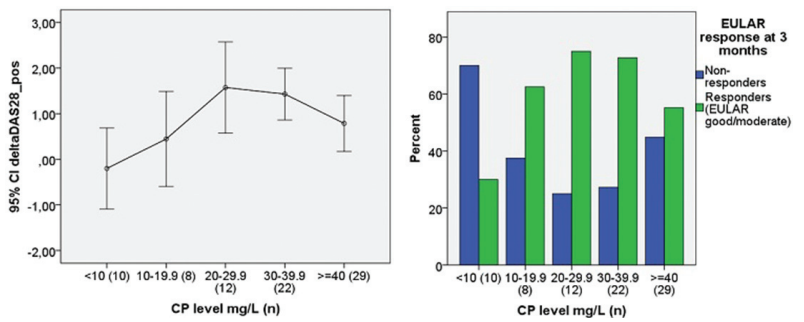

Conclusions: Certolizumab serum levels $\geq 20 \mathrm{mg} / \mathrm{L}$ were associated with DAS28 improvement, but not significantly with EULAR response after 3 months treatment in RA pts. We suggest $20 \mathrm{mg} / \mathrm{L}$ as a lower target limit for non-trough CP samples in RA-patients. No additional benefit of having a certolizumab level over $40 \mathrm{mg} / \mathrm{L}$ was observed.

\section{REFERENCE:}

[1] Jani M, et al. AnnRheum Dis 2017;76(1):208-13.

Disclosure of Interest: J. E. Gehin Consultant for: Roche, S. Syversen Consultant for: Roche, D. Warren: None declared, G. Goll Consultant for: Abbvie, Biogen, Boehringer Ingelheim, Orion Pharma, Eli Lilly, Novartis, Pfizer, MSD, Roche, UCB, J. Sexton: None declared, E. Strand Consultant for: Pfizer, T. Kvien Consultant for: AbbVie, Biogen, BMS, Boehringer Ingelheim, Celgene, Celltrion, Eli Lilly, Epirus, Hospira, Merck-Serono, MSD, Mundipharma, Novartis, Oktal, Orion Pharma, Hospira/Pfizer, Roche, Sandoz, UCB, N. Bolstad Consultant for: Pfizer, Orion Pharma, Napp pharmaceuticals, Takeda, Roche, E. Lie: None declared DOI: 10.1136/annrheumdis-2018-eular.5160

\section{SAT0186 TREATMENT RESPONSE OF INTRAVENOUS TOCILIZUMAB IN PATIENTS WITH RHEUMATOID ARTHRITIS BASED ON THE LEVEL OF PRIOR EXPOSURE TO BIOLOGIC THERAPY: RESULTS FROM THE KOBIO}

K. Shin ${ }^{1}$, S.-K. Lee ${ }^{1}$, S. Oh ${ }^{2}$, H.-A. Kim ${ }^{3}$, Y. W. Song ${ }^{4} .{ }^{1}$ Division of Rheumatology, ${ }^{2}$ Department of Biostatistics, Seoul Metropolitan Government-Seoul National University Hospital Boramae Medical Center, Seoul, ${ }^{3}$ Division of Rheumatology, Ajou University School of Medicine, Suwon, ${ }^{4}$ Division of Rheumatology, Seoul National University Hospital, Seoul, Korea, Republic Of

Background: Previous studies have showed that response rate to biologic therapy in patients with rheumatoid arthritis (RA) are lower in those who had prior exposure to multiple biologic agents compared with first-time users. However, most of these studies targeted on patients undergoing anti-TNF therapy.

Objectives: To investigate the treatment response of RA patients using intravenous tocilizumab (TOC) as the first biologic agent, comparing with those who had prior exposure to other biologic agents

Methods: Data of RA patients treated with TOC were obtained from the Korean College of Rheumatology Biologics Registry (KOBIO). Patients were grouped as first (1st)-line, second (2nd)-line, and third or more ( $\geq 3 \mathrm{rd}$ )-line users. Clinical outcomes including SDAI changes at the first year and second year of TOC therapy were evaluated, and subsequent switching to another biologic agent and its associated factors were analyzed using the Cox proportional hazard model.

Results: A total of 408 patients were included in the study; 1 st-line $(n=258)$, 2nd -line $(n=95), \geq 3$ rd -line $(n=55)$ users. The mean age was 54.0 years, and mean disease duration of 8.2 years. At baseline, mean SDAI was 30.0, and $7.1 \%$ of patients were treated without a concomitant conventional DMARD, which increased to $21.6 \%$ at the end of the second year. The clinical response of related parameters in 1st -line TOC users were more robust than the 2 nd -line or $>3 \mathrm{rd}$ line users, and greater proportion of 1 st -line users achieved remission or low disease activity at the second year ( $p=0.00291)$ (figure). In addition, switching to another agent was more frequent in the 2 nd -line or $\geq 3$ rd -line users within 2 years (1st, 2nd, $\geq 3$ rd -line users, $4.7 \%, 15.1 \%, 11.1 \%$, respectively). A multivariate analysis revealed that higher baseline SDAI (HR 1.1018, $p=0.00680)$ and multiple prior exposure to biologics (HR 2.5751, $p=0.0139$ ) were predictors of subjects switching to other agents.

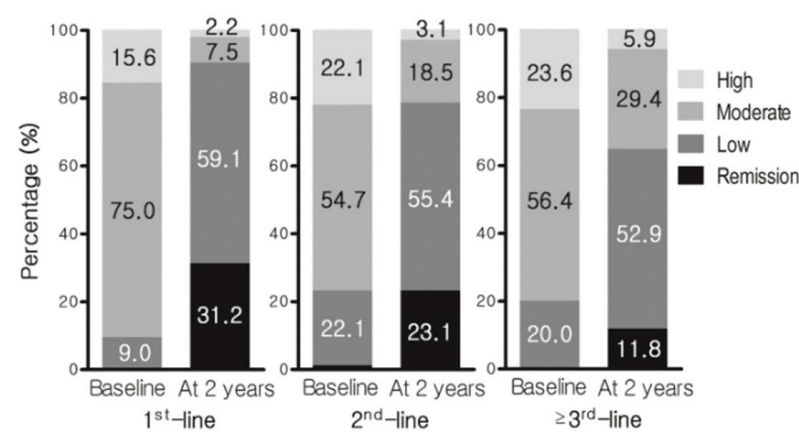

Conclusions: Amongst RA patients with high disease activity who receive TOC, patients naïve to biologics have better treatment response and lower switch rates after two years.

\section{REFERENCE:}

[1] Karlsson JA, et al. Treatment response to a second or third TNF-inhibito in RA: results from the South Swedish Arthritis Treatment Group Register. Rheumatology 2008;47:507-13.

Disclosure of Interest: None declared

DOI: 10.1136/annrheumdis-2018-eular.6111

\section{SAT0187 GOLIMUMAB IMPROVES WORK PRODUCTIVITY AND ACTIVITY IMPAIRMENT IN PATIENTS WITH RHEUMATOID ARTHRITIS (RA), ANKYLOSING SPONDYLITIS (AS) AND PSORIATIC ARTHRITIS (PSA): 1-YEAR RESULTS FROM A NON- INTERVENTIONAL TRIAL IN GERMANY}

I. Klaudius ${ }^{1}$, K. Krueger ${ }^{2}$, S. Remstedt ${ }^{3}$, A. Thiele ${ }^{4} .{ }^{1} M S D$ Sharp \& Dohme GmbH, ${ }^{2}$ Praxiszentrum St. Bonifatius, Munich, ${ }^{3}$ Rheuma Praxis, Berlin, ${ }^{4}$ Krankenhaus St. Josef, Wuppertal, Germany

Background: Non-interventional studies (NIS) are essential instruments in phar maceutical research not only for pharmaceutical companies but also for regulatory authorities or reimbursement bodies in Germany.

Aside from direct costs caused by a disease, German sick funds as well as health authorities have a keen interest in indirect costs, such as costs derived from loss of work productivity.

Objectives: It is the aim of this study to show the benefit of Golimumab (GLM) in work productivity and activity for RA, AS and PsA patients in Germany. The analy sis was performed using the validated indication-specific Work Productivity Activity Impairment (WPAI) Questionnaire as primary endpoint. The WPAI is rated to be the most psychometrically validated and frequently used instrument for measuring of health-related work-productivity.

Methods: As primary endpoint, the change of work productivity impairment and ability for daily activities in month $3(\mathrm{~V} 1)$ versus baseline visit (V0) was evaluated. All 4 subscores of the WPAI were analysed: disease related absence from work (absenteeism), working while sick (presenteeism), total work productivity impairment (TWPI) and activity impairment with TWPI as primary score.

In addition, an evaluation of the activity impairment in the mITT population (modified-Intention-To-Treat) was performed.

As exploratory endpoint, the change in work productivity/activity impairment after 6 months and 12 months versus baseline as measured by WPAI for PsA, RA and AS patients treated with Golimumab in German clinical practice was evaluated.

Results: Of 748 patients $(100 \%)$ who started treatment with Golimumab at V0 (baseline), $666(89.0 \%), 634(84.8 \%)$ and 552 patients $(73.8 \%)$ continued treatment until V1 (Month 3), V2 (Month 6), and V3 (Month 12/end of observation period), respectively.

Efficacy analyses were performed on the mITT population which included 700 patients $(R A=237, P s A=235, A S=228)$ who had at least 2 documented visits.

The statistically significant improvements (all p-values $<0.05$ ) in the mean WPA domain scores were maintained over the 12-month observation period in all 3 indications with a higher treatment effect regarding "activity impairment" and "presenteeism" than with "absenteeism". The magnitude of improvements in the 4 WPA domains and the time course of improvements varied between the underlying dis ease (RA, PSA, AS)

In general, the improvements in the 4 WPAI domains were greater in patients with AS and PsA compared to RA patients. A continuous improvement over time was seen in AS patients regarding the domain "activity impairment. A positive effect of pre-treatment with biologics (i.e. better improvement in WPAI) was seen in RA 